\title{
Seroprevalence of SARS-CoV-2 IgM and IgG antibodies in an asymptomatic population in Sergipe, Brazil
}

\author{
Lysandro Pinto Borges ${ }^{1}$, Aline Fagundes Martins², Mônica Santos de Melo², \\ Makson Gleydson Brito de Oliveira², José Melquiades de Rezende Neto², \\ Marcos Barbosa Dósea1, Bruna Cecília Maia Cabral', Rafael Fontes Menezes', \\ Aryanne Araujo Santos ${ }^{1}$, Igor Leonardo Santos Matos ${ }^{1}$, Pamela Chaves Borges ${ }^{1}$, \\ Kezia Alves dos Santos ${ }^{1}$, Anderson Alves Ribeiro ${ }^{3}$, Andres Ignacio Martinez Menendez ${ }^{1}$, Mairim \\ Russo Serafini', Cristiani Banderó Walker ${ }^{1}$, Lucindo José Quintans Junior ${ }^{1}$, Adriano Antunes de Souza \\ Araújo' ${ }^{1}$ and Daniela Raguer Valadão de Souza²
}

Suggested citation Borges LP, Martins AF, Melo MS, Oliveira MGB, Neto JMR, Dósea MB et al. Seroprevalence of SARS-CoV-2 IgM and IgG antibodies in an asymptomatic population in Sergipe, Brazil. Rev Panam Salud Publica. 2020;44:e108. https://doi.org/10.26633/ RPSP.2020.108

ABSTRACT

Objective. To estimate the prevalence of SARS-CoV-2 antibodies in an asymptomatic population in the state of Sergipe, Brazil.

Methods. This cross-sectional study with stratified sampling (sex and age) included serological immunofluorescent tests for IgM and IgG on samples from 3046 asymptomatic individuals. Sample collection was performed in wet-markets of the 10 most populous cities of Sergipe, Brazil. Exclusion criteria included symptomatic individuals and health workers. The presence of comorbidities was registered.

Results. Of the 3046 participants, 1577 (51.8\%) were female and 1469 (48.2\%) were male; the mean age was 39.76 (SD 16.83) years old. 2921 tests were considered valid for IgM and 2635 for IgG. Of the valid samples, 347 (11.9\% [Cl 10.7\%-13.1\%]) tested positive for IgM and 218 (8.3\% [Cl 7.2\%-9.4\%]) tested positive for IgG. Women over 40 had the highest prevalence for IgM (group C, $p=0.006$; group D p=0.04). The capital Aracaju displayed the highest prevalence for both antibodies; 83 (26.3\% [Cl 21.6\%-31.6\%]) tested positive for IgM and 35 (14.6\% [Cl 10.4\%-19.7\%]) for IgG. The most prevalent comorbidities were hypertension (64/123 individuals) and diabetes (29/123).

Conclusions. A high prevalence of SARS-CoV-2 antibodies was found among asymptomatic persons in Sergipe. Women over 40 showed the highest rates. The capital, Aracaju, displayed the highest seroprevalence. Surveys like this one are important to understand how the virus spreads and to help authorities to plan measures to control it. Repeated serologic testing are required to track the progress of the epidemic.

Keywords Asymptomatic infections; seroepidemiologic studies; coronavirus infections; asymptomatic infections; Brazil.

In December 2019, a new virus (SARS-CoV-2, the causative pathogen for COVID-19) emerged in Wuhan, Hubei Province, China, and rapidly spread worldwide (1). On 30 January 2020, the World Health Organization (WHO) declared that the new coronavirus outbreak constituted a Public Health Emergency of International Concern (2).

\footnotetext{
Federal University of Sergipe, Sao Cristovao, Brazil. $\triangle$ Makson Gleydson Brito de Oliveira, makson_gbo@hotmail.com
} 
By May 23, 2020, SARS-CoV-2 had been detected in almost every country, with more than 5.37 million confirmed cases and a death toll exceeding 342555 (3). Epidemiologic data $(4,5)$ suggest that human-to-human transmission has accounted for most infections.

In the absence of effective pharmaceutical measures for prevention or treatment, the $\mathrm{WHO}$ recommends a combination of non-pharmaceutical interventions (NPIs): rapid diagnosis and immediate isolation of cases, rigorous tracking and precautionary self-isolation of close contacts (6).

The impact of isolation and contact tracing, however, is uncertain and highly dependent on the number of asymptomatic cases $(7,8)$. Asymptomatic persons are potential sources of SARS-CoV-2 infection, presenting strong infectivity during the incubation-period and rapid transmission $(9,10)$. Hence, a far greater portion of the population might be exposed to the virus than documented $(11,12)$. Therefore, estimating the prevalence of these unreported infections is critical for understanding the overall prevalence and pandemic potential of this disease (11). Serology tests may be an important tool to determine prevalence, virus lethality, and provide information about immunity and risk factors such as the patient's age, location, or underlying health conditions (13). Testing with appropriate data interpretation, contact tracing and self-isolation of positive cases and close contacts, is critical to prevent transmission and extinguish outbreaks $(14,15)$.

In Brazil, coronavirus is advancing exponentially, with over 390000 confirmed cases and more than 24000 deaths (16). In Sergipe, a state in the northeast of Brazil, the first SARS-CoV-2 infection was confirmed on March 14, 2020, in a person who had just returned from Spain (17). Sergipe has a population of over two million inhabitants and has the fourth highest reported incidence of COVID-19 among the states in the Northeast of Brazil, with 249 cases per 100000 people $(16,18)$.

In Brazil, understanding the true prevalence of COVID-19 is vital; however, the lack of mass testing makes it difficult to implement measures to ensure appropriate quarantine of positive cases (19). In Sergipe, tests are only performed in symptomatic individuals, which can lead to a significant underestimation of the SARS-CoV-2 prevalence. Therefore, this study sought to estimate the seroprevalence of SARS-CoV-2 infection in Sergipe in an asymptomatic population.

\section{MATERIAL AND METHODS}

\section{Study design and specimen collection}

Targeted testing involved individuals who were deemed to be asymptomatic for SARS-CoV-2 infection. Symptomatic individuals (cough, fever, body aches, and shortness of breath) were excluded from the sample, as were health workers, as they were more likely to have had contact with the virus and, therefore, bias the results of the study.

Population screening for SARS-CoV-2 occurred from May 2 to May 9, and was performed in the 10 most populous cities of Sergipe. Asymptomatic residents at the main wet-market of each city at the time of the study were enrolled in the study after giving their informed consent. Personal data including age, gender, address, presence of any comorbidities and symptoms compatible with COVID-19 were gathered through an online questionnaire (www.monitorasus.ufs.br) performed by a health care worker just before blood sample collection. Venous blood samples were collected and centrifuged for serum separation.

The sample size for each tested city was calculated based on the Brazilian Institute of Geography and Statistics (IBGE) population proportion data. A total of 3,046 people were enrolled in this investigation, and the participants were categorized in four groups according to age and gender as follows: A: 0 to 19 years old (men and women), B: 20 to 39 years old (men and women), C: 40 to 59 years old (men and women) and D: over 60 years old (men and women). Within each group, men and women were recruited to match the characteristics of the population.

The participants received the serological result through a telephone text message sent between May 10 and May 17. In order to support the ongoing public health response, all participants who tested positive for SARS-CoV-2 antibodies were contacted by phone by staff from the designated authorities to track the infection. Antibody-positive participants and their contacts were required to self-isolate and to self-quarantine for 14 days, respectively. All data were recorded in MonitoraSUS (www. monitorasus.ufs.br), a web system created by our research group to record virological exam results, georeference each patient, and integrate the results with those reported by other Brazilian states and cities (this system will be described in detail in another report that is currently being prepared for publication).

The study was approved by the National Bioethics Committee of Brazil (CAAE 31018520.0.0000.5546).

\section{Laboratory analysis}

Immunofluorescence assays were performed at the Department of Pharmacy Laboratory (Laboratory of Biochemistry and Clinical Immunology, LaBiC-Imm) at the Federal University of Sergipe (UFS). Anti-SARS-CoV-2 IgM and IgG antibodies were detected in sera using an in vitro diagnostic test system based on lateral flow sandwich detection immunofluorescence technology (Ichroma2 ${ }^{\mathrm{TM}}$ COVID-19 Ab in conjunction with an Ichroma ${ }^{\mathrm{TM}}$ II Reader, Boditech Med Inc., South Korea) according to the manufacturer's instructions. The immunofluorescence method applied showed a sensitivity of $95.8 \%$ and a specificity of $97 \%$. A validation study was performed using 120 serum samples collected from 60 real-time reverse transcription polymerase chain reaction ( $r$ RT-PCR) confirmed COVID-19 cases, and 60 negative patients at different clinical sites.

\section{Statistical analysis}

We used Clopper-Pearson exact method to calculate $95 \%$ confidence intervals, implemented in the $\mathrm{R}$ package binom. We also used stratified sampling (20) by demographic characteristics (sex and age range), considering the population characteristics of the cities and a possible prevalence difference caused by social distancing measures. Sample collection was carried out in wet-markets, which are very popular in the state and bring together people from all social classes, and was open to all symptom-free people in each stratum.

Regarding the statistical analysis of the results, it is known [see for instance (21)] that the likelihood ratio $(L R)$ for a positive/negative test result is given by

$$
L R+=\frac{s e}{1-s p} \quad L R-=\frac{1-s e}{s p}
$$


where se is the true-positive rate (sensitivity) and $s p$ the true-negative rate (specificity), that can be put in terms of True Positive results (TP), False Negative results (FN), False Positive results (FP) and True Negative results (TN),

$$
s e=\frac{T P}{T P+F N}(1) \text { and } \quad 1-s e=\frac{T P}{F P+T N} \text { (2). }
$$

Furthermore, we assume that Positive Test Results (PTR) is the sum of True Positive results (TP) with False Positive results (FP), and Negative Test Results (NTR) is the sum of True Negative results (TN) with False Negative results (FN), that is $P T R=T P+F P(3)$ and $N T R=T N+F N(4)$. With equations (1) to (4) it is easy to show that:

$$
\begin{gathered}
T P=\frac{P T R \times s p-N T R \times(1-s p)}{s e \times s p-(1-s p) \times(1-s e)} \times s e \\
F N=\frac{P T R \times s p-N T R \times(1-s p)}{s e \times s p-(1-s p) \times(1-s e)} \times(1-s e) .
\end{gathered}
$$

We also have prevalence $=(T P+F N) /$ total validtests. The method used has $s e=95 \%$ and $s p=97 \%$.

\section{RESULTS}

A total of 3047 people were tested; however, one person was from another state and was excluded from the survey. Of the 3 046 samples tested, 1577 (51.8\%) were female and 1469 (48.2\%) were male, and all participants provided consent. The mean age was 39.76 (SD 16.83) years old. Among tested individuals 362 (11.9\%) were from Group A: 191 (6.3\%) females and 171 (5.6\%) males); 1243 (40.8\%) were from Group B: 634 (20.8\%) females and $609(20.0 \%)$ males; 1,027 (33.7\%) were from Group C: 541 $(17.7 \%)$ females and $486(16.0 \%)$ males; and $414(13.6 \%)$ were from Group D: 211 (6.9\%) females and 203 (6.7\%) males. Of the 3046 participants, 2921 tests were considerable valid for IgM and 2635 for IgG. So, of the valid samples, 347 (11.9\% [10.7\% $13.1 \%]$ ) tested positive for $\operatorname{IgM}$ (indicating an active/recent infection) and $218(8.3 \%$ [CI, 7.2\% - 9.4\%]) tested positive for IgG (indicating a past infection). Of the $347(11.9 \%$ [10.7\% - 13.1\%]) which tested positive for IgM, 47 (1.6\% [CI, 1.2\% - 2.1\%]) were also positive for $\operatorname{IgG}$, indicating a recent infection that may still be contagious. Of the IgG valid samples, only those which were positive for IgG and negative for IgM were considered. The fraction that tested positive varied by sex and age (Table 1).

The proportion of women positive for $\operatorname{IgM}(14.7 \%$ [12.9\% $16.5 \%)$ was higher than that of men $(\operatorname{IgM} 8.9 \%[7.5 \%-10.5 \%])$ $(\mathrm{p}<0.0001)$. Although there was no significant difference in positive cases (IgM reagent) between men and women in groups $\mathrm{A}$ and $B$, in groups $C(p=0.0032)$ and $D(p=0.005)$, the difference was quite significant. In addition, among the female groups, Group B showed the lowest prevalence of infection (B - C $\mathrm{p}=0.0017$ and $\mathrm{B}-\mathrm{D} \mathrm{p}=0.03)$. Women over 40 had higher prevalence rates for IgM antibodies when compared to men (women in group C showed a prevalence of $17.7 \%$ [14.5\% - 21.3\%] and men $9.8 \%(7.3 \%-12.9 \%$ ], $\mathrm{p}<0.0005$; women in group D showed a prevalence of $16.9 \%$ [12.1\% - 22.7\%] and men $6.4 \%$ [3.5\% $10.8 \%$ ], $\mathrm{p}<0.001)$. There was no significant difference in the prevalence of IgG antibodies in terms of either gender or age.

The 10 cities studied were ranked according to their distribution of positive cases for IgM and IgG (Table 2). Aracaju, the state capital, was classified as the city with the highest seroprevalence for both IgM and IgG, with 83 (26.3\% of the total assessed cases in that city [CI, $21.6 \%-31.6 \%$ ]) and $35(14.6 \%$ of the total assessed cases in that city [CI, 10.4\% - 19.7\%]) cases, respectively; followed by Simão Dias, that presented $37(16.0 \%$ of the

\begin{tabular}{|c|c|c|c|c|c|c|}
\hline \multirow{3}{*}{ Variable } & \multicolumn{6}{|c|}{ Seroprevalence } \\
\hline & \multicolumn{6}{|c|}{$p=0.05$} \\
\hline & \multicolumn{3}{|c|}{ Reagent IgM } & \multicolumn{3}{|c|}{ Reagent $\lg G$} \\
\hline & Valid samples & Positive & $\%(95 \% \mathrm{Cl})$ & Valid samples & Positive & $\%(95 \% \mathrm{Cl})$ \\
\hline Total Gender & 2921 & 347 & $11.9(10.7-13.1)$ & 2635 & 218 & $8.3(7.2-9.4)$ \\
\hline Female & 1500 & 220 & $14.7(12.9-16.5)$ & 1327 & 117 & $8.8(7.3-10.5)$ \\
\hline \multirow[t]{3}{*}{ Male } & 1421 & 127 & $8.9(7.5-10.5)$ & 1308 & 101 & $7.7(6.3-9.3)$ \\
\hline & \multicolumn{6}{|c|}{$\lg M$ reagent } \\
\hline & & Female & & & Male & \\
\hline Group Age range & Valid samples & Positive & $\%(95 \% \mathrm{CI})$ & Valid samples & Positive & $\%(95 \% \mathrm{CI})$ \\
\hline Group A & 178 & 27 & $15.2(10.2-21.3)$ & 167 & 16 & $9.6(5.6-15.1)$ \\
\hline Group B & 601 & 67 & $11.1(8.7-13.9)$ & 584 & 52 & $8.9(6.7-11.5)$ \\
\hline Group C & 514 & 91 & $17.7(14.5-21.3)$ & 469 & 46 & $9.8(7.3-12.9)$ \\
\hline \multirow[t]{3}{*}{ Group D } & 207 & 35 & $16.9(12.1-22.7)$ & 201 & 13 & $6.4(3.5-10.8)$ \\
\hline & \multicolumn{6}{|c|}{$\lg G$ reagent } \\
\hline & & Female & & & Male & \\
\hline Group Age range & Valid samples & Positive & $\%(95 \% \mathrm{Cl})$ & Valid samples & Positive & $\%(95 \% \mathrm{CI})$ \\
\hline Group A & 161 & 11 & $6.8(3.5-11.9)$ & 151 & 7 & $4.6(1.9-9.3)$ \\
\hline Group B & 554 & 43 & $7.8(5.7-10.3)$ & 543 & 39 & $7.2(5.1-9.7)$ \\
\hline Group C & 440 & 38 & $8.6(6.2-11.7)$ & 429 & 39 & $9.1(6.5-12.2)$ \\
\hline Group D & 172 & 25 & $14.5(9.6-20.7)$ & 185 & 16 & $8.6(5.0-13.7)$ \\
\hline
\end{tabular}

TABLE 1. SARS-CoV-2 seroprevalence in asymptomatic individuals in the 10 most populous cities in the state of Sergipe, Brazil, May 2020 
TABLE 2. Rank of distribution of positive cases for IgM and IgG in the 10 most populous cities in the state of Sergipe, Brazil, May 2020

\begin{tabular}{|c|c|c|c|c|c|c|}
\hline \multirow[t]{2}{*}{ Cities } & \multicolumn{3}{|c|}{ IgM seroprevalence } & \multicolumn{3}{|c|}{$\lg G$ seroprevalence } \\
\hline & Valid samples & Positive & $\%(\mathrm{Cl} 95 \%)$ & Valid samples & Positive & $\%(\mathrm{Cl} 95 \%)$ \\
\hline Aracaju & 315 & 83 & $26.3(21.6-31.6)$ & 240 & 35 & $14.6(10.4-19.7)$ \\
\hline Simão Dias & 231 & 37 & $16.0(11.5-21.4)$ & 202 & 12 & $5.9(3.1-10.1)$ \\
\hline Itabaianinha & 272 & 36 & $13.2(9.4-17.8)$ & 246 & 25 & $10.2(6.7-14.6)$ \\
\hline Nossa Senhora do Socorro & 293 & 31 & $10.6(7.3-14.7)$ & 277 & 32 & $11.5(8.0-15.9)$ \\
\hline Lagarto & 294 & 22 & $7.5(4.7-11.1)$ & 272 & 23 & $8.4(5.4-12.4)$ \\
\hline Tobias Barreto & 298 & 14 & $4.7(2.6-7.7)$ & 287 & 6 & $2.1(0.1-4.5)$ \\
\hline Nossa Senhora da Glória & 259 & 12 & $4.6(2.4-7.9)$ & 243 & 20 & $8.2(5.1-12.4)$ \\
\hline
\end{tabular}

FIGURE 1. Distribution of IgM-reactive individuals according to their main comorbidities by age group in the state of Sergipe, Brazil, May 2020

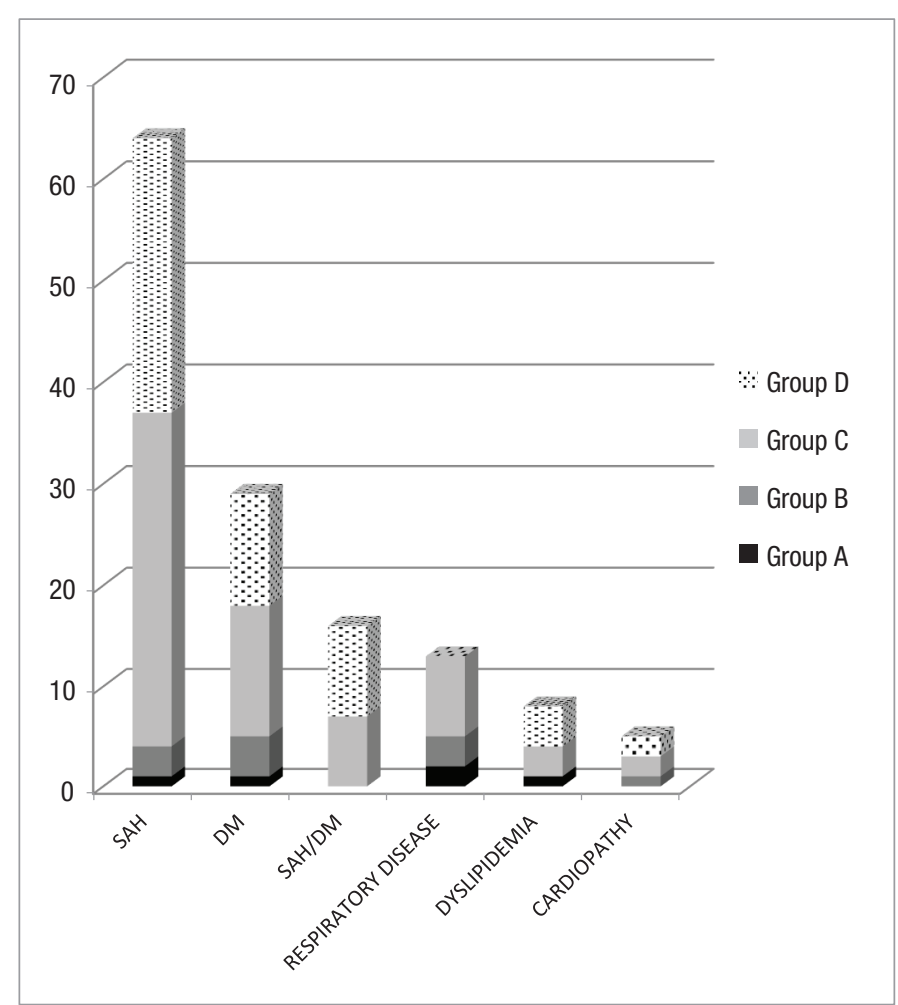

Group A, 0-19 years; Group B, 20-39 years; Group C, $40-59$ years; Group D, +60 years $\mathrm{SAH}$, systemic arterial hypertension; DM, diabetes mellitus

total assessed cases in that city [CI, 11.5\% - 21.4\%]) and $12(5.9 \%$ of the total assessed cases in that city [CI, 3.1\% - 10.1\%]) cases; Itabaiana, that presented $55(14.8 \%$ of the total assessed cases in that city [CI, 11.4-18.9]) and 17 of the total assessed cases in that city $(5.4 \%$ [CI, 3.1\% - 8.4\%]) cases, being the three cities with the highest seroprevalence of SARS-CoV-2 in the state.

Individuals reacting to $\operatorname{IgM}$ were evaluated for their comorbidities (Figure 1): systemic arterial hypertension, diabetes mellitus, respiratory disease (sinusitis, rhinitis, bronchitis, among others), dyslipidemia, heart disease, obesity, and others.
The most prevalent comorbidity was hypertension, which presented 64/123 individuals who were reactive for IgM; followed by diabetes mellitus, which presented 29/123 IgM-reactive individuals. Subsequently, we presented the overlap of two comorbidities, hypertension and diabetes mellitus, with 16 individuals reactive for IgM. The individuals reactive for IgM with respiratory diseases, such as rhinitis, bronchitis and sinusitis, totaled 13. On the other hand, individuals with dyslipidemia who showed reactivity to $\operatorname{IgM}$, totaled 8 . Finally, individuals with heart disease positive for IgM, totaled 5. Other comorbidities appeared less significantly, with a low prevalence. There was no IgG positive patients reporting the presence of comorbidities. Figure 1 shows data on the distribution of comorbidities of individuals positive for $\operatorname{IgM}$ and categorized by age groups, including the greatest prevalence in the age group $\mathrm{C}$.

\section{DISCUSSION}

In face of the current public health emergency, serological testing may be a helpful tool to suppress human-to-human transmission of COVID-19 $(13,22)$. The use of serological tests in the asymptomatic population or those presenting mild symptoms is fundamental, as these persons are not tested for viral RNA, thereby masking the population's true rate of infection (22). Studies $(7,11,23,24)$ have shown that a great number of persons who tested positive for SARS-CoV-2 reported no symptoms. In Sergipe, official case counts rely on tests performed on symptomatic persons, hence, the true rate of infection is probably underestimated.

In our study, we conducted serologic tests to estimate the prevalence of SARS-CoV-2 infection in asymptomatic persons, as serologic tests identify both active and past infections. Our findings demonstrate that of the valid samples, $347(11.9 \%)$ tested positive for $\operatorname{IgM}$ and $218(8.3 \%)$ tested positive for IgG.

Studies targeting asymptomatic individuals $(16,23,25)$ have reported a wide range of prevalence for positive cases that seems to be related to the characteristics of the population and the efforts of local authorities to contain transmission of the virus. The importance of NPIs on reducing the infection rate was observed in Vo, Italy, where prevalence estimates showed a significant decrease after a period of lockdown, suggesting that viral transmission could be effectively suppressed by combining the early isolation of detected cases with social distancing (26). The mitigation measures implemented by the Icelandic 
health care authorities are thought to be responsible for the low prevalence of the disease seen in the general population, which was less than 1\% (23). Conversely, the high prevalence of positive cases seen in the present study seems to be consistent with the difficulty of implementing social distancing (which is less than $50 \%$ ), despite the strict measures applied (17).

The selection biases inherent in different sample selection strategies and the methodologies applied also has implications for the prevalence range observed in studies. An rRT-PCR study (24) conducted with 215 pregnant women presenting for delivery showed a prevalence of $13.7 \%$ of asymptomatic, positive cases for SARS-CoV-2. Another rRT-PCR study testing for SARSCoV-2 among 131 patients presenting influenza-like illness (27), found a prevalence rate of $5.3 \%$. In Iceland, rRT-PCR testing of 9199 people at high risk for infection revealed a prevalence of $13.3 \%$ for SARS-CoV-2, while of 643 tests performed in the general population only $0.8 \%$, in the open-invitation screening, and $0.6 \%$, in the random-population screening, tested positive (23). In Los Angeles, serological assays were carried out on a random sample of residents who were invited to participate in the study and the prevalence of antibodies to SARS-CoV-2 found was $4.65 \%$ (25). Seroprevalence of antibodies to SARS-CoV-2 in Santa Clara County was estimated as $2.8 \%$ in tests comprising 3330 individuals recruited using Facebook ads (28). A serological survey (29) was also conducted in New York State, including New York City, which sampled 3000 individuals shopping in grocery and big-box stores. The preliminary findings of the research suggested that $21 \%$ of the participants were positive for coronavirus antibodies. Toulis (13) used a New York State serology study and estimated a COVID-19 prevalence for this population as high as $11-18 \%$. As in New York, our seroprevalence results for the Sergipe population show high rates, possibly due to similarities in sampling selection, as we recruited participants in wet-markets around the state.

In Switzerland, serosurveys targeting exclusively IgG antibodies for SARS-CoV-2 (30) were conducted in asymptomatic individuals enrolled in the Geneva Bus Santé study. ELISA results based on 1335 people revealed a prevalence of $9.7 \%$. Interestingly, our findings for IgG antibodies show a similar score of $8.3 \%$. Estimating IgG prevalence is extremely important in terms of returning to work, although there is no evidence supporting whether this antibody may function as an "immunity passport" (31). Overall, our IgG data suggest that the epidemic is far from burning out simply due to herd immunity.

In our study, $51.77 \%$ of all participants were female and $48.23 \%$ male, displaying a similar distribution to that of the overall population of Sergipe (18). The prevalence of women who tested positive for IgM antibodies was significantly higher when compared to men, which is in agreement with official estimates for the state (17).

The quotas used in the enrollment process for the subgroups based on age were in accordance with official figures for the age profile of the population (18). The fraction that tested positive for IgM and IgG antibodies varied by gender and age. In Brazil, the median age of patients who tested positive for COVID-19 is 40 years old $(66.76 \%)$ (16). In agreement, our results show that group C (40-50 years of age) presented the highest prevalence for IgM antibodies for both, men and women. Interestingly, group A (0-19 years of age) also revealed a high prevalence for IgM antibodies, suggesting that despite young people being less likely to have severe disease, they get infected at similar rates; this is in line with other studies $(8,32)$. Notably, we also found high rates of IgM and IgG prevalence for group D (+60 years), implying that targeted efforts to reduce the social mixing of older adults have not succeeded.

In Italy, a statistical model estimating the prevalence of COVID-19 exhibited varying data among the Italian regions, from $0.35 \%$ infection rate in Sicily and Basilicata to $11.2 \%$ in Lombardy (32). Our results also showed different prevalence rates according to geographical areas, ranging from $4.6 \%$ to $26.3 \%$ for IgM antibodies (in Nossa Senhora da Glória and Aracaju, respectively), and from $2.1 \%$ to $14.6 \%$ for IgG antibodies (in Tobias Barreto and Aracaju, respectively). Again, we believe the differences observed were related to overall containment measures and mitigation, which have shown different levels of compliance throughout the state (17). Aracaju, the capital of Sergipe, is the business and economic center of the state, has an airport and is on the main commercial routes; it also has the largest population of the municipalities tested. The first case of COVID-19 in the state was also found in Aracaju. The city has a social distancing rate of only $39 \%$ (17); therefore, it was expected to have the highest prevalence of IgM and IgG antibodies. Our findings corroborate other data in Brazil showing that COVID19 cases are increasing in smaller cities (16), especially in more densely populated regions facing difficulties in establishing true and effective social distancing (19). Our results show that Tobias Barreto and Nossa Senhora da Glória displayed the lowest prevalence, possibly due to the strict policies applied in these cities regarding the control of commercial activities (17).

Comorbidities have been directly associated with the severity of coronavirus disease $(33)$. Studies $(33,34)$ revealed that, in general, patients treated in intensive care units and who receive invasive mechanical ventilation are mainly male, elderly and present various comorbidities. In Wuhan, about $32 \%$ of COVID19 patients admitted to the hospital had underlying diseases including diabetes, hypertension and cardiovascular disease. (34) Yang et al. (33) assessed the prevalence of comorbidities in COVID-19 patients in seven different studies in the Chinese population, and found that the most prevalent comorbidities were hypertension and diabetes. Likewise, our findings indicate hypertension and diabetes as the most prevalent comorbidities among patients tested positive for IgM antibodies.

This study has some limitations. First, selection bias is likely as the sample may include those who naturally tend to go out more, and so were more likely to be exposed to the virus; and those who were already concerned about potential infection. Second, prevalence estimates may change with new information on the accuracy of the test kits used. Third, the incidence of infection over time was not assessed. Repeated serologic testing in different locations, spaced a few weeks apart is required to track the progress of the epidemic in the population of Sergipe.

Nonetheless, serological testing has become an extremely helpful tool in epidemiology, since it is able to detect recent and past infections, including asymptomatic and recovered cases, providing better information regarding disease prevalence in a population. Other advantages include its scalability and antibody stability, which allows its use on a large scale in the population. (35)

In conclusion, the current study attempted to estimate the true prevalence of COVID-19 in Sergipe, Brazil, taking into account the fact that the asymptomatic population may be largely responsible for the spread of the virus. This is the first Brazilian study that uses immunofluorescence assay for SARS-CoV-2 antibodies in a wide range of the population, and the rate of $11.9 \%$ for 
IgM antibodies among an asymptomatic population is concerning. Knowing the prevalence of antibodies to the virus in the population is important in terms of understanding its spread, and implementing measures to control it. However, it is not yet known how much, if any, immunity the presence of antibodies gives to individuals, or for how long. Our data suggest that the high seroprevalence observed in Sergipe is intimately related to the low levels of social distancing. Seroprevalence surveys, like this one, are necessary to inform and assist global policymakers in planning measures that could alleviate the economic burden of the disease, and prevent the collapse of the healthcare system.

Authors' contributions. All authors have read and agreed to the published version of the manuscript.
Funding. The authors themselves.

Acknowledgments. To all health professionals who are facing COVID-19. We thank the Ministry of Labour and the Federal and State Public Ministries for facilitating the testing described in this article. We are eternally grateful, and hope that our article can contribute to reducing the number of deaths.

\section{Conflicts of interest. None declared.}

Disclaimer. Authors hold sole responsibility for the views expressed in the manuscript, which may not necessarily reflect the opinion or policy of the RPSP/PAJPH and/or PAHO.

\section{REFERENCES}

1. The 2019-nCoV Outbreak Joint Field Epidemiology Investigation Team, Qun Li. An Outbreak of NCIP (2019-nCoV) Infection in China [Wuhan, Hubei Province]. China CDC Weekly. 2020; 2(5): 79-80.

2. World Health Organization. Statement on the second meeting of the International Health Regulations Emergency Committee regarding the outbreak of novel coronavirus (2019nCoV) [Accessed 23 May 2020] https:/ / www.who.int/news-room/ detail/23-01-2020-statement-on-the-meeting-of-the-internationalhealth-regulations-(2005)-emergency-committee-regarding-theoutbreak-of-novel-coronavirus-(2019-ncov).

3. The Worldometer. COVID-19 CORONAVIRUS PANDEMIC [Accessed 23 May 2020] https://www.worldometers.info/ coronavirus $/$ ?utm_campaign=homeAdvegas1?

4. Chan JFW, Yuan S, Kok KH, To KKW, Chu H, Yang J, et al. A familial cluster of pneumonia associated with the 2019 novel coronavirus indicating person-to-person transmission: a study of a family cluster. Lancet. 2020;395:514-23.

5. Li Q, Guan X, Wu P, Wang X, Zhou L, Tong Y, et al. Early Transmission Dynamics in Wuhan, China, of Novel Coronavirus-Infected Pneumonia. N Engl J Med. 2020;382:1199-207.

6. World Health Organization. Report of the WHO-China Joint Mission on Coronavirus Disease 2019 (COVID-19) [Accessed 23 May 2020]. https://www.who.int/docs/default-source/coronaviruse/ who-china-joint-mission-on-covid-19-final-report.pdf

7. Arons MM, Hatfiled KM, Reddy SC, Kimball A, James A, Jacobs JR, et al. Presymptomatic SARS-CoV-2 Infections and Transmission in a Skilled Nursing Facility. N Engl J Med. 2020;382:2081-90.

8. Bi Q, Wu Y, Mei S, Ye C, Zou X, Zhang Z, et al. Epidemiology and Transmission of COVID-19 in 391 Cases and 1286 of Their Close Contacts in Shenzhen, China: A Retrospective Cohort Study. Lancet Infect Dis. 2020;S1473-3099:30287-5.

9. Huang L, Zhang X, Zhang X, Wei Z, Zhang L, Xu J, et al. Rapid Asymptomatic Transmission of COVID-19 During the Incubation Period Demonstrating Strong Infectivity in a Cluster of Youngsters Aged 16-23 Years Outside Wuhan and Characteristics of Young Patients With COVID-19: A Prospective Contact-Tracing Study. J Infect. 2020;80:e1-e13.

10. Rothe C, Schunk M, Sothmann P, Bretzel G, Froeschl G, Wallrauch C, et al. Transmission of 2019-nCoV Infection from an Asymptomatic Contact in Germany. N Engl J Med. 2020; 82:970-1.

11. Li R, Pei S, Chen B, Song Y, Zhang T, Yang W, et al. Substantial Undocumented Infection Facilitates the Rapid Dissemination of Novel Coronavirus (SARS-CoV-2). Science. 2020;368:489-93.

12. Abduljalil JM, Abduljalil BM. Epidemiology, genome, and clinical features of the pandemic SARS-CoV-2: a recent view. New Microbes New Infect. 2020;35:100672.

13. Toulis P. Estimation of COVID-19 Prevalence from Serology Tests: A Partial Identification Approach, Working paper NO. 2020-54 [cited 05/23/2020] https://bfi.uchicago.edu/work ing-paper/estimation-of-covid-19-prevalence-from-serology-tests-apartial-identification-approach/
14. Salathé M, Althaus CL, Neher R, Stringhini S, Hodcroft E, Fellay J, et al. COVID-19 epidemic in Switzerland: on the importance of testing, contact tracing and isolation. Swiss Med Wkly. 2020;150:w20225.

15. Koks S, Williams RW, Quinn J, Farzaneh F, Conran N, Tsai SJ, et al. COVID-19: Time for precision epidemiology. Exp Biol Med (Maywood). 2020;245:677-679.

16. Brazil. Health Ministry. Secretary of Health Surveillance. [Accessed 23 May 2020] https:/ / covid.saude.gov.br/

17. Sergipe. Secretary of Health [Accessed 23 May 2020] https:/ /www. saude.se.gov.br/

18. Brazilian Institute of Geography and Statistics. [Accessed 23 May 2020] https://cidades.ibge.gov.br/brasil/se/panorama

19. Dantas RCC, Campos PA, Rossi I, Ribas RM. Implications of social distancing in Brazil in the COVID-19 pandemic. Infect Control Hosp Epidemiol. 2020;8:1-2.

20. Bussab WO, Bolfarine H. Elementos de amostragem. São Paulo: Editora E. Blücher, 2005

21. Habibzadeh F, Habibzadeh P. The likelihood ratio and its graphical representation. Biochem Med (Zagreb). 2019;29:020101.

22. Infantino M, Damiani A, Gobbi FL, Grossi V, Lari B, Macchia D, et al. Serological Assays for SARS-CoV-2 Infectious Disease: Benefits, Limitations and Perspectives. Isr Med Assoc J. 2020;22:203-10.

23. Gudbjartsson DF, Helgason A, Jonsson H, Magnusson OT, Melsted P, Norddahl GL, et al. Spread of SARS-CoV-2 in the Icelandic Population. N Engl J Med. 2020;14.

24. Sutton D, Fuchs K, D'Alton M, Goffman D. Universal Screening for SARS-CoV-2 in Women Admitted for Delivery. N Engl J Med. 2020;382:2163-4.

25. Sood N, Simon P, Ebner P, Eichner D, Reynolds J, Bendavid E. Seroprevalence of SARS-CoV-2-Specific Antibodies Among Adults in Los Angeles County, California, on April 10-11, 2020. JAMA. 2020;18.

26. Lavazzo E, Franchin E, Ciavarella C, o-Dannenburg GC, Barzon L, Del Vecchio C, et al. Suppression of COVID-19 outbreak in the municipality of $\mathrm{Vo}^{\prime}$, Italy. medRxiv. 2020.

27. Spellberg B, Haddix M, Lee R, Butler-Wu S, Holtom P, Yee H, et al. Community Prevalence of SARS-CoV-2 Among Patients With Influenza like Illnesses Presenting to a Los Angeles Medical Center in March 2020. JAMA. 2020;323:1966-7.

28. Bendavid E, Mulaney B, Sood N, Shah S, Ling E, Bromley-Dulfano $\mathrm{R}$, et al. COVID-19 Antibody Seroprevalence in Santa Clara County, California. medRxiv. 2020.

29. Goodman JD, Rothfeld M. 1 in 5 New Yorkers May Have Had Covid19, Antibody Tests Suggest. 2020 [Accessed 23 May 2020] https:// www.nytimes.com/2020/04/23/nyregion/coronavirus-antibodies-test-ny.html

30. Stringhini S, Wisniak A, Piumatti G, Azman AS, Lauer SA, Baysson $\mathrm{H}$, et al. Repeated seroprevalence of anti 1 -SARS-CoV-2 IgG antibodies in a population-based sample. medRxiv. 2020.

31. Mallapaty S. Will coronavirus antibody tests really change everything? Nature. 2020;580:571-2. 
32. Signorelli C, Scognamiglio T, Odone A. COVID-19 in Italy: impact of containment measures and prevalence estimates of infection in the general population. Acta Biomed. 2020; 91:175-9.

33. Yang J, Zheng Y, Gou X, Pu K, Chen Z, Guo Q, et al. Prevalence of Comorbidities and Its Effects in Patients Infected With SARS-CoV-2: A Systematic Review and Meta-Analysis. Int J Infect Dis. 2020;94:9195. doi: 10.1016/j.ijid.2020.03.017

34. Huang C, Wang Y, Li X, Ren L, Zhao J, Hu Y, et al. Clinical Features of Patients Infected With 2019 Novel Coronavirus in Wuhan, China. Lancet. 2020;395:497-506.
35. Younes N, Al-Sadeq DW, Al-Jighefee H, et al. Challenges in Laboratory Diagnosis of the Novel Coronavirus SARS-CoV-2. Viruses. 2020;12(6):E582. .

Manuscript received on 14 June 2020. Revised version accepted for publication on 23 July 2020.

\section{Seroprevalencia de los anticuerpos IgM e IgG del SARS-CoV-2 en una población asintomática en Sergipe, Brasil}

RESUMEN Objetivo. Estimar la prevalencia de anticuerpos dirigidos contra el SARS-CoV-2 en una población asintomática del estado de Sergipe, Brasil.

Métodos. Estudio transversal con muestreo estratificado (por sexo y edad) que incluyó pruebas serológicas de inmunofluorescencia para IgM e IgG en muestras de 3046 individuos asintomáticos. La recolección de muestras se realizó en los mercados húmedos de las 10 ciudades más pobladas de Sergipe, Brasil. Se excluyó a los individuos sintomáticos y a los trabajadores de la salud. Se registró la presencia de comorbilidades.

Resultados. De los 3046 participantes, 1577 (51,8\%) eran mujeres y 1469 (48,2\%) varones; la edad promedio fue de 39,76 (SD 16,83) años. Se consideraron válidas 2921 pruebas para la IgM y 2635 para la lgG. De las muestras válidas, $347(11,9 \%$ [Cl 10,7\%-13,1\%]) resultaron positivas para IgM y $218(8,3 \%$ [Cl 7,2\%-9,4\%]) para IgG. Las mujeres mayores de 40 años tuvieron la mayor prevalencia de IgM (grupo C, p=0,006; grupo D, $\mathrm{p}=0,04)$. Aracaju, la capital del estado, mostró la mayor prevalencia para ambos anticuerpos; $83(26,3 \%[\mathrm{Cl}$ $21,6 \%-31,6 \%])$ resultaron positivas para IgM y 35 (14,6\% [Cl 10,4\%-19,7\%]) para IgG. Las comorbilidades más frecuentes fueron la hipertensión (64/123 individuos) y la diabetes (29/123).

Conclusiones. Se encontró una alta prevalencia de anticuerpos contra el SARS-CoV-2 en personas asintomáticas en Sergipe. Las mujeres mayores de 40 años mostraron las tasas más altas. La capital, Aracaju, mostró la mayor seroprevalencia. Las encuestas como esta son importantes para comprender cómo se propaga el virus y para ayudar a las autoridades a planificar medidas de control. Se requieren pruebas serológicas repetidas para dar seguimento al progreso de la epidemia.

Palabras clave Infecciones asintomáticas; estudios seroepidemiológicos; infecciones por coronavirus; Brasil. 